\title{
Thermal behavior of PLA plasticized by commercial and cardanol-derived plasticizers and the effect on the mechanical properties
}

\author{
Antonio Greco ${ }^{1}\left[\right.$ Francesca Ferrari $^{1}$
}

Received: 19 June 2020 / Accepted: 11 November 2020 / Published online: 27 November 2020

(c) The Author(s) 2020

\begin{abstract}
This paper is aimed at studying the thermal properties of poly(lactic acid), PLA with different plasticizers. Plasticized PLA was obtained by mixing and extruding PLA with 20 mass\% of neat cardanol, epoxidized cardanol acetate (ECA) and poly(ethylene glycol) (PEG) 400. The glass transition of completely amorphous samples, melting and crystallization behavior of plasticized PLA were analyzed by differential scanning calorimetry. Results obtained show that, below $T_{\mathrm{g}}$, a higher enthalpy relaxation occurs for PLA plasticized by cardanol derivatives. This is indicative of a faster mobility of PLA chains below $T_{\mathrm{g}}$, when cardanol derivatives are used as plasticizers. On the other hand, an opposite behavior was observed for the crystallization studies. In facts, a much faster crystallization was found for PLA plasticized by PEG, which in turn indicates a much higher mobility of PLA chains above $T_{\mathrm{g}}$ compared to PLA plasticized by cardanol derivatives. Mechanical properties obtained on completely amorphous samples show that PLA plasticized by ECA is characterized by lower modulus, which is indicative of a more efficient plasticization. On the other hand, the thicker crystals formed during crystallization of PLA plasticized by ECA involve a more relevant increase in the modulus in semicrystalline samples.
\end{abstract}

Keywords PLA $\cdot$ Plasticizer $\cdot$ Glass transition $\cdot$ Crystallization $\cdot$ Modulus

\section{Introduction}

Recently, environmental concerns and a decrease in petroleum availability led to bulk production of bio-based materials $[1,2]$. Among them, poly(lactic acid) (PLA), a biodegradable, aliphatic polyester derived from lactic acid, is a promising polymer for the replacement of petroleum derivatives [3]; PLA main features, such as high biodegradability and good mechanical response, with stiffness and strength comparable to those of polystyrene, allowed its use for several industrial applications [4]. Moreover, thermal and rheological properties of PLA allow its processing with a wide range of industrial techniques, such as injection molding, extrusion, thermoforming, fiber spinning and calendaring $[5,6]$.

Antonio Greco

Antonio.greco@unisalento.it

1 Department of Engineering for Innovation, University of Salento, via per Arnesano, 73100 Lecce, Italy
Nevertheless, PLA usage can be limited because of its high brittleness, which poses severe limitations in terms of processability and end-use mechanical performances. On the other hand, the ductility of PLA can be improved by copolymerization, or by the addition of plasticizers [7].

Being the addition of plasticizers much more cost-effective, it is often preferred to copolymerization; in particular, plasticizer addition allows a decrease in glass transition temperature and an increase in toughness of the polymer $[8,9]$. Although several plasticizers, both biodegradable and non-biodegradable, were blended with PLA to obtain its plasticization [10], low molecular weight poly(ethylene glycol) (PEG) showed the best performances in terms of plasticizing effectiveness [11, 12]. On the other hand, a good alternative to PEG can be found in bio-plasticizers, such as cardanol, derived from natural oil and properly modified to improve the compatibility with PLA. Cardanol, a phenolic oil obtained by vacuum distillation of "cashew nut shell liquid" (CNSL), is a natural, cheap plasticizer with low toxicological impact; being a waste of cashew nut industry, it has a positive environmentally impact and does not involve the use of primary resources [13]. Cardanol is employed for coating 
manufacturing, in the chemical industry for the production of soluble resins, for rubber compounding, for high-grade insulating varnishes, paints, enamels [14, 15]. Many studies were carried out about the use of cardanol and its derivatives for the plasticization of polymers, in particular PVC [16-18].

The efficiency of cardanol and its derivatives as plasticizer for PLA was assessed in previous works [18]. Cardanol used in this work was subjected to acetylation, thus obtaining cardanol acetate (CA), and to further epoxidation, thus realizing epoxidized cardanol acetate (ECA).

This work is aimed to study the influence of different plasticizers on the crystallization rate of PLA.

Many studies were carried out in order to verify the influence of the cooling rate on the crystallization of enantiomerically pure PLA [19, 20]. It was found that high crystalline fraction, characterized by large spherulites, was reached with cooling rates lower than $2{ }^{\circ} \mathrm{C} \min ^{-1}$. On the other hand, a complete amorphous polymer was obtained with cooling rates equal or higher than of $20{ }^{\circ} \mathrm{C} \mathrm{min}^{-1}$ [21]. Moreover, lower molecular weights and, as a consequence, higher chain mobility involve an increase in crystallization degree [22]. In this work, DSC analyses were carried out to study the influence of the plasticizer on the crystallization kinetic, and its plasticizing effect on the amorphous and crystalline phase. Furthermore, X-ray diffraction (XRD) analyses were performed to confirm the degree of crystallinity of plasticized PLA found with differential scanning calorimetry (DSC) tests. Finally, mechanical properties of completely amorphous and crystalline plasticized PLA were investigated. Compared to our previous paper [18], the aim of this work is more focused on the correlation between mechanical and thermal properties. In particular, more attention was paid to the study of the crystallization kinetics, as well as to the structural relaxation occurring below $T_{\mathrm{g}}$.

\section{Materials and methods}

PLA used in this work is the polyester Ingeo Biopolymer 2003D, supplied by NatureWorks (Minnetonka, MN US), with a density of $1.24 \mathrm{~g} \mathrm{~cm}^{-3}$ and a melt flow rate of $6 \mathrm{~g} / 600 \mathrm{~s}$ at $210^{\circ} \mathrm{C}$. According to the technical data sheet, the polymer mainly consists of Lisomer, with the $\mathrm{D}$-isomer content lower than $4 \%$. PEG, characterized by a molecular weight MW $=400 \mathrm{~g} \mathrm{~mol}^{-1}$, supplied by Sigma-Aldrich (St. Louis, MO, USA). Technical cardanol, with a purity of $95 \%$, was supplied by Oltremare (Bologna, Italy). Epoxidized cardanol acetate (ECA) was provided by Serichim (Torviscosa, Udine, Italy) and was obtained by acetylation and further epoxidation of cardanol [23]. The material is characterized by a yield of epoxidation of about $81 \%$ with an average molecular weight of about $370 \mathrm{~g} \mathrm{~mol}^{-1}$. Plasticized PLA films, with an average thickness of $0.15 \mathrm{~mm}$, were obtained by extruding PLA mixed with $20 \%$ of each plasticizer in a HAAKE POLYLAB SYSTEM twin screw extruder, using the following temperature profile from the feeder zone to the die: $190,190,180,180,165,160$ and $140{ }^{\circ} \mathrm{C}$, and a screw speed of $15 \mathrm{rpm}$. The extruding cooling conditions allowed producing amorphous films, as confirmed by DSC and XRD analyses.

Annealing of plasticized PLA films was performed by heating in static oven at $90{ }^{\circ} \mathrm{C}$ for $1 \mathrm{~h}$, which allowed to obtain fully crystalline samples. Also in view of the potential plasticizer migration, the mass loss during the annealing treatment was found to be in any case lower than $0.1 \%$, which indicates the negligible mass loss due to thermal treatment.

DSC analysis was performed on a Mettler Toledo 822 (Mettler Toledo, Greifensee, Switzerland) instrument under a nitrogen flux of $60 \mathrm{~mL} \min ^{-1}$, applying different scan methods:

- In order to evaluate the glass transition temperature for a completely amorphous material, a first heating scan was performed between -120 and $200{ }^{\circ} \mathrm{C}$ at $10{ }^{\circ} \mathrm{C} \mathrm{min}^{-1}$, followed by a rapid cooling to $-100{ }^{\circ} \mathrm{C}$ at $50{ }^{\circ} \mathrm{C} \mathrm{min}^{-1}$ and a second heating scan at $10{ }^{\circ} \mathrm{C} \mathrm{min}^{-1}$ up to $200{ }^{\circ} \mathrm{C}$.

- In order to measure the melting behavior of plasticized PLA crystallized at different temperatures, a first heating up to $200{ }^{\circ} \mathrm{C}$ was applied, followed by quenching at $50{ }^{\circ} \mathrm{C} \mathrm{min}^{-1}$ to $0{ }^{\circ} \mathrm{C}$; this allowed to avoid melt crystallization, thus obtaining a fully amorphous material. After, the sample was heated at $50{ }^{\circ} \mathrm{C} \mathrm{min}{ }^{-1}$ to the isothermal crystallization temperature and held for $15 \mathrm{~min}$, followed by cooling at $50{ }^{\circ} \mathrm{C} \mathrm{min}-1$ to $0{ }^{\circ} \mathrm{C}$, and a final heating at ${ }^{\circ} \mathrm{C} \mathrm{min}^{-1}$ up to $200{ }^{\circ} \mathrm{C}$. The melting temperature of the sample was measured during the last heating scan.

- In order to monitor the crystallization process, all the plasticized samples were cooled from 200 to $-20{ }^{\circ} \mathrm{C}$ at different cooling rates (specifically, 0.75, 1, 1.25 and $1.5^{\circ} \mathrm{C} \mathrm{min}^{-1}$ for PLA_ECA samples, $1.25,1.5,1.75$ and $2{ }^{\circ} \mathrm{C} \mathrm{min}^{-1}$ for PLA_CARD samples and 1.5, 2, 2.5 and $3{ }^{\circ} \mathrm{C} \mathrm{min}^{-1}$ for PLA_PEG samples). For each sample, the cooling rates were chosen in order to obtain a final degree of crystallinity after cooling between 0.05 and 0.3 .

XRD analysis (Rigaku, Tokyo, Japan) was carried out with CuKa radiation $\left(k=1.5418 \mathrm{~A}^{\circ}\right)$ in the step scanning mode recorded in the $2 \mathrm{~h}$ range of $10^{\circ}-40^{\circ}$, with a step size of $0.02^{\circ}$ and step duration of $0.5 \mathrm{~s}$. Finally, tensile tests were performed on plasticized PLA samples on a LLoyd LR50K dynamometer according to ASTM D638 standard, using $50 \mathrm{~mm} \mathrm{~min}^{-1}$ crosshead speed and $100 \times 10 \times 0.15 \mathrm{~mm}$ samples. For each measurement, 6 specimens were used, in order to assess the change in the mechanical properties resulting from different degrees of crystallinity. 


\section{Results and discussion}

\section{Glass transition of plasticized PLA}

The glass transition signals of the CARD and ECA plasticizers are reported in Fig. 1, and the relative measured values of $T_{\mathrm{g}}$ and $\Delta c_{\mathrm{p}}$ are reported in Table 1 . In the range of DSC experiments, no glass transition signal was detected for neat PEG. The values of $T_{\mathrm{g}}$ and $\Delta c_{\mathrm{p}}$ were also estimated by the group contribution method [24-26]. For CARD and ECA plasticizer, comparison between experimental and predicted data shows an excellent agreement. Therefore, it was possible to use the same procedure for calculating the corresponding thermal parameters for PEG. The estimated value for PEG, $T_{\mathrm{g}}=-136^{\circ} \mathrm{C}$, falls out of the measuring range of the DSC instrument used in this work. The glass transition temperature of the plasticizer is of particular relevance for the final glass transition temperature of the plasticized PLA. According to the results of Table 1, for the same amount of added plasticizer, the $T_{\mathrm{g}}$ of PLA plasticized by PEG is expected to be lower than that of PLA plasticized by CARD or ECA.

The group contribution method applied to the specific heat discontinuity provides a less accurate estimation of the experimental value, with an average error or $20 \%$.

The glass transition signals of fully amorphous plasticized PLA are reported in Fig. 2, and the values of $T_{\mathrm{g}}$, calculated at the midpoint, are reported in Table 2 . Therefore, the $T_{\mathrm{g}}$ signals of Fig. 2 are obtained on completely amorphous samples. PLA_PEG and PLA_CARD are characterized by comparable values of the glass transition temperatures. The $T_{\mathrm{g}}$ of PLA_ECA is about $5^{\circ} \mathrm{C}$ higher than that of the other two samples.

Also, for comparison purposes, the values of $T_{\mathrm{g}}$ calculated according to the Fox or Gordon-Taylor equations are

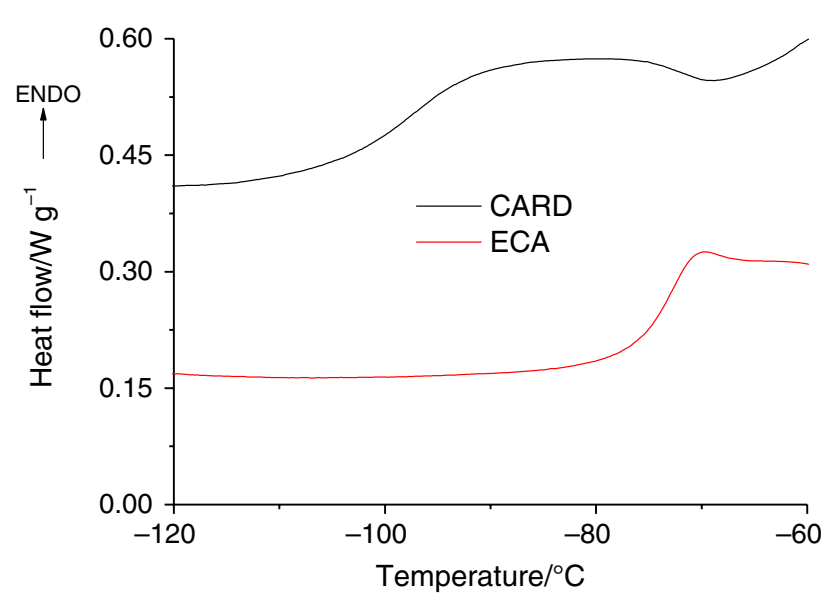

Fig. 1 Glass transition signals of CARD and ECA
Table 1 Experimental and estimated glass transition temperatures and specific heat discontinuities for PLA and plasticizers

\begin{tabular}{lcclll}
\hline & \multicolumn{2}{c}{$T_{\mathrm{g}}{ }^{\circ} \mathrm{C}$} & & \multicolumn{2}{c}{$\Delta c_{\mathrm{p}} / \mathrm{J} \mathrm{kg}^{-1} \mathrm{~K}^{-1}$} \\
\cline { 2 - 3 } \cline { 5 - 6 } & Experimental & Estimated & & Experimental & Estimated \\
\hline PLA & 59 & 68 & & 540 & 350 \\
PEG & & -136 & & 975 \\
CARD & -103 & -103 & & 916 & 763 \\
ECA & -74 & -76.5 & & 898 & 744 \\
\hline
\end{tabular}

reported. For the Gordon-Taylor equation, the value of $K_{\mathrm{GT}}=\frac{\Delta c_{\mathrm{p}, \mathrm{plast}}}{\Delta c_{\mathrm{p}, \mathrm{pLA}}}$ was used [27], using the estimated $\Delta c_{\mathrm{p}}$ values of Table 1.

As it can be observed, both models predict for PLA_PEG a $T_{\mathrm{g}}$ which is much lower than the experimental value. This indicates that probably some phase segregation occurs during processing [28]; PEG is not completely absorbed by PLA, and therefore, the resulting glass transition is higher than that of the predicted one. On the other hand, also for PLA_CARD a small difference (about $6-9{ }^{\circ} \mathrm{C}$ ) between the model prediction and experimental $T_{\mathrm{g}}$ value indicates the partial absorption of the plasticizer in the PLA domains. Finally, for PLA_ECA the very good agreement between model and experimental $T_{\mathrm{g}}$ indicates that the plasticizer is fully absorbed by PLA during processing. By comparison with the data of Table 1, the higher $T_{\mathrm{g}}$ found for PLA_ECA is therefore due to the higher glass transition of the ECA plasticizer.

In addition to the glass transition signals, the curves of Fig. 2 show a significant enthalpy recovery peak, which is associated with structural relaxation occurring below $T_{\mathrm{g}}[29$, $30]$. The area of the recovery peak, estimated after isothermal relaxation at different temperatures, ranging between 0 and $15^{\circ} \mathrm{C}$, is reported in Fig. 3 as a function of the degree of

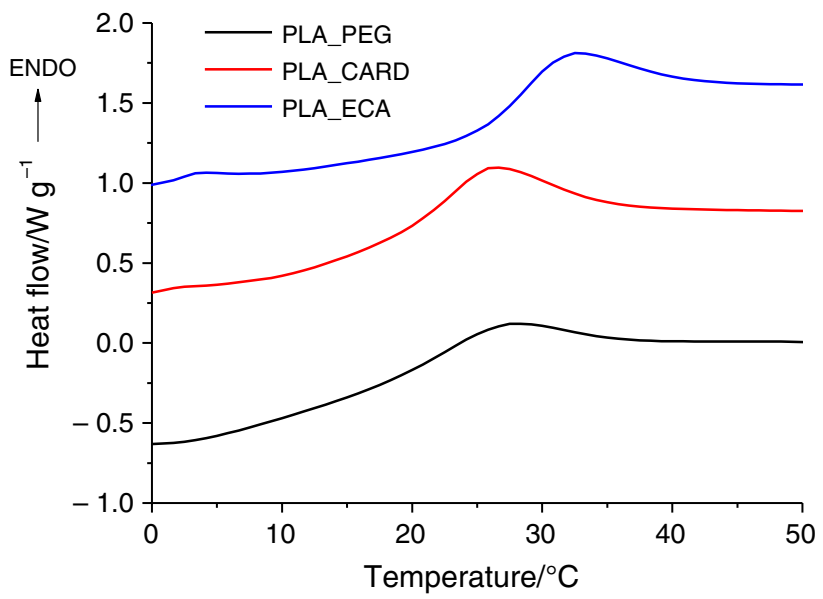

Fig. 2 Glass transition signals of plasticized PLA 
Table 2 Experimental and estimated glass transition temperatures and specific heat discontinuities for plasticized PLA

\begin{tabular}{lllcc}
\hline & $T_{\mathrm{g}} \mathrm{\rho}{ }^{\circ} \mathrm{C}$ & $\Delta c_{\mathrm{p}} / \mathrm{J} \mathrm{kg}^{-1} \mathrm{~K}^{-1}$ & $T_{\mathrm{g}}{ }^{\circ} \mathrm{C}$ Fox model & $\begin{array}{l}T_{\mathrm{g}}{ }^{\circ} \mathrm{C} \text { Gor- } \\
\text { don-Taylor } \\
\text { model }\end{array}$ \\
\hline PLA_PEG & $17.5 \pm 2.3$ & $642 \pm 20$ & -10.2 & -15.7 \\
PLA_CARD & $16.9 \pm 2.6$ & $490 \pm 95$ & 10.9 & 7.7 \\
PLA_ECA & $22.3 \pm 3.1$ & $670 \pm 18$ & 24.3 & 17.8 \\
\hline
\end{tabular}

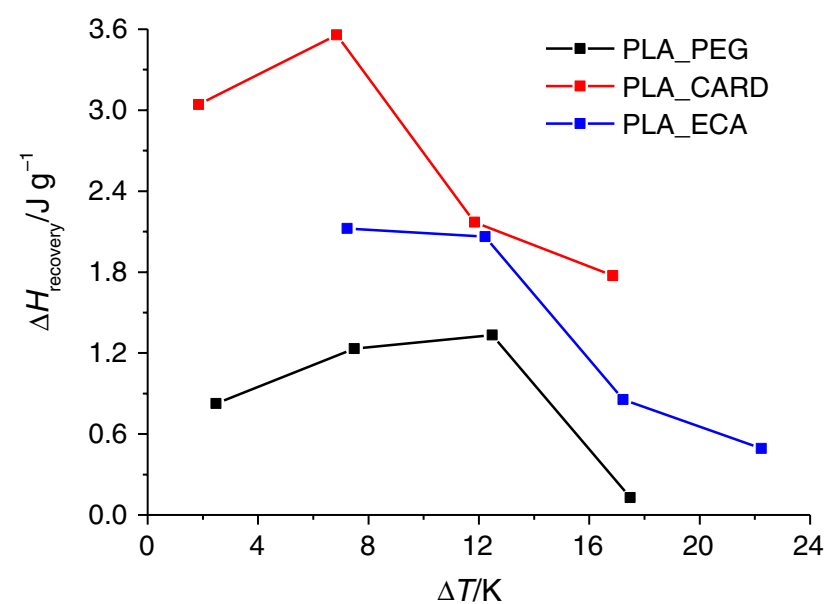

Fig. 3 Enthalpy recovery peak for plasticized PLA

undercooling below $T_{\mathrm{g}}$. As clearly observed, PLA plasticized PEG shows relatively low recovery, as compared to PLA_ ECA and PLA_CARD. In particular, the latter shows the higher values of enthalpy recovery, which is associated with higher enthalpy relaxation below $T_{\mathrm{g}}$. The results reported indicate that the PLA plasticized by PEG is characterized by lower mobility below $T_{\mathrm{g}}$, whereas the PLA_CARD is characterized by higher mobility.

\section{Melting of plasticized PLA}

Typical DSC curves obtained during the final heating after isothermal crystallization for $15 \mathrm{~min}$ at $75{ }^{\circ} \mathrm{C}$ are reported in Fig. 4. Melting curves of plasticized PLA are characterized by multiple endothermic peaks, which result from recrystallization and lamellar thickening occurring during heating. In particular, recrystallization occurs through the transformation of the disordered $\alpha^{\prime}$ crystalline form, produced during the melt crystallization at low temperatures, into the ordered $\alpha$ form [31]. In addition, for the same crystallization temperature and time for crystallization, neat PLA shows a very low melting enthalpy, which results from the very low rate of crystallization of the specific grade of PLA. The addition of plasticizer involves in any case an increase in the melting enthalpy, which indicates a higher degree of crystallinity attained in the isothermal step at the crystallization temperature. However,

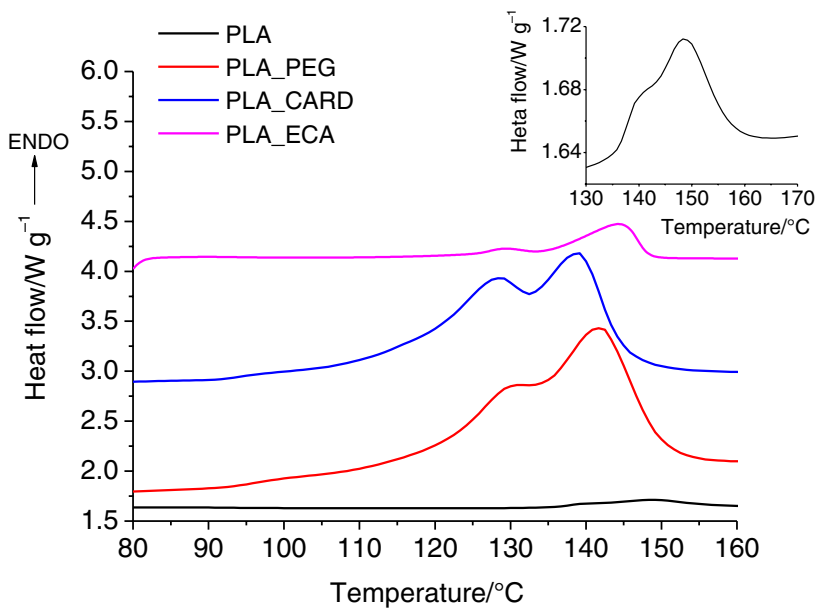

Fig. 4 Melting traces of plasticized PLA after isothermal crystallization at $90{ }^{\circ} \mathrm{C}$

such increase is more relevant for PEG and CARD plasticizer, whereas PLA_ECA is characterized by a melting enthalpy which is much lower than that of the other two plasticized samples. The different behavior during crystallization of plasticized PLA will be discussed in the next section.

All the curves are characterized by a melting range which is well below the melting range measured for neat PLA [32] and also observed in the inset of Fig. 4. This is in agreement with the prediction from the Flory-Huggins equation, which allows to correlate the melting temperature of the polymer blend or polymer solution to the melting temperature of the pure polymer [33]:

$$
\begin{aligned}
& \frac{1}{T_{\mathrm{m}}^{0}(\text { blend })}-\frac{1}{T_{\mathrm{m}}^{0} \text { (polymer) }} \\
& \quad=\frac{R}{\Delta H} \frac{v_{\mathrm{u}, \mathrm{PLA}}}{v_{\mathrm{u}, \text { plast }}}\left[\left(1-\phi_{\mathrm{PLA}}\right)-\chi\left(1-\phi_{\mathrm{PLA}}\right)^{2}\right]
\end{aligned}
$$

where $T_{\mathrm{m}}^{0}$ (blend) and $T_{\mathrm{m}}^{0}$ (polymer) are the equilibrium melting temperature of the plasticized PLA (the blend with plasticizer) and neat polymer, respectively, $\Delta H=6770 \mathrm{~J} \mathrm{~mol}^{-1}$ is the melting enthalpy of neat polymer, $v_{\mathrm{u}, \mathrm{PLA}}$ and $v_{\mathrm{u}, \mathrm{PLAST}}$ are the molar volume of neat polymer and plasticizer, and $\phi_{\text {PLA }}$ is the volume fraction of polymer in the blend. The Flory-Huggins interaction parameter, $\chi$, was estimated as: 
$\chi=0.34+\frac{V_{\mathrm{u}, \text { plast }}}{R T}\left(\delta_{\mathrm{PLA}}-\delta_{\text {plast }}\right)^{2}$

where $\delta_{\mathrm{PLA}}$ and $\delta_{\text {plast }}$ are the Hansen solubility parameter of PLA and plasticizer, respectively, and the constant value 0.34 represents the entropic contribution. The prediction for the different parameters of Eqs. (1) and (2), obtained according to group contribution method [25], is reported in Table 3.

Although the equilibrium melting temperature of PLA is usually reported to be in the range of $200-210{ }^{\circ} \mathrm{C}$, it has also been shown to significantly depend on different factors, among which the molecular weight is the most important [34]. Therefore, the equilibrium melting temperature of the PLA used in this work needs to be experimentally determined.

By changing the isothermal temperature of crystallization, the equilibrium melting temperature can be obtained by the Hoffmann-Weeks theory, as reported in Eq. (3):

$T_{\mathrm{m}}=T_{\mathrm{m}}^{0}\left(1-\frac{1}{\gamma}\right)+\frac{T_{\mathrm{C}}}{\gamma}$

where $T_{\mathrm{c}}$ is the isothermal crystallization temperature, $T_{\mathrm{m}}$ is the corresponding melting temperature, $\gamma$ is the thickening factor, and $T_{\mathrm{m}}^{0}$ represents the equilibrium melting temperature.

The more relevant issue associated with the use of Eq. (3) is the choice of the melting temperature to be used for the Hoffmann-Weeks plot. In facts, the value of $T_{\mathrm{m}}$ should represent the melting temperature of the crystals originally formed during crystallization at $T_{\mathrm{c}}$. On the other hand, the presence of multiple peaks in Fig. 4 highlights the existence of recrystallization and/or lamellar thickening, which continuously change the size of the crystals originally formed at $T_{\mathrm{c}}$. Therefore, this makes impossible to use, for example, the melting peak temperature in the Hoffmann-Weeks plot. This is highlighted in the results reported in Fig. 5 for PLA_PEG, where the Hoffmann-Weeks plot is reported at different values of degree of melting. The degree of melting was obtained by diving the melting enthalpy $\Delta H_{\mathrm{m}}$ by $\Delta H_{\mathrm{m}}^{0}=93 \mathrm{~J} \mathrm{~g}^{-1}$, which is

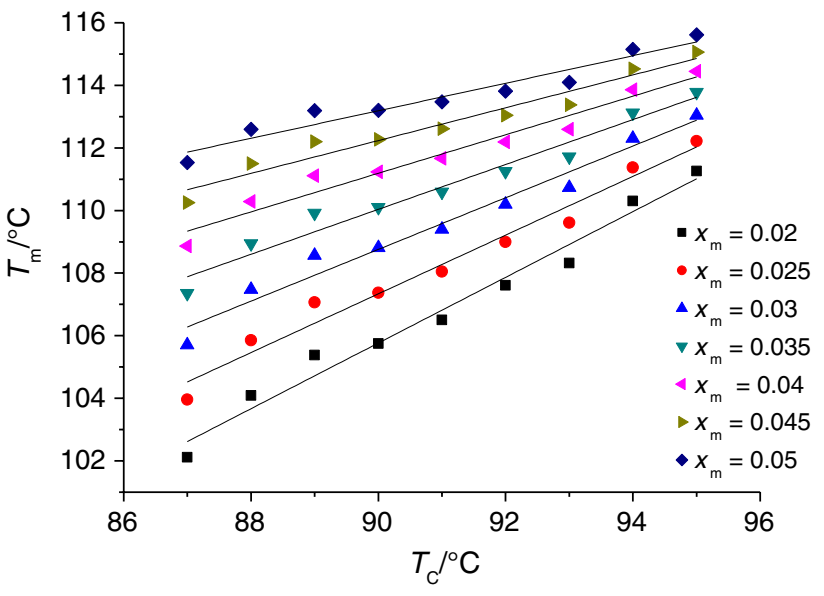

Fig. 5 Hoffmann-Weeks plot for PLA_PEG at different degrees of melting

the melting enthalpy of fully crystalline PLA [35], corrected by the amount of PLA in the mixtures:

$x_{\mathrm{m}}(T)=\frac{\Delta H_{\mathrm{m}}(T)}{w_{\mathrm{PLA}} \Delta H_{\mathrm{m}}^{0}}$

In order to build the plots of Fig. 5, for each degree of melting the corresponding temperature was found, and then, it was plotted as a function of the corresponding crystallization temperature. From the results of Fig. 5, it is clear that the slope of the linear fitting curves increases as $x_{\mathrm{m}}$ increases. This corresponds to a reduction of the lamellar thickening factor as the degree of melting increases. Different approaches have been proposed in order to overcome the issues associated with the Hoffmann-Weeks plot [36, 37]; however, in the present case, for each value of the degree of melting a plot of the value of $T_{\mathrm{m}}$ versus $T_{\mathrm{C}}$ is used to calculate an extrapolated value of temperature, according to:

$T_{\mathrm{m}}=T_{\text {extr }}\left(x_{\mathrm{m}}\right)\left(1-\frac{1}{\gamma\left(x_{\mathrm{m}}\right)}\right)+\frac{T_{\mathrm{C}}}{\gamma\left(x_{\mathrm{m}}\right)}$

where both $T_{\text {extr }}\left(x_{\mathrm{m}}\right)$ and $\gamma\left(x_{\mathrm{m}}\right)$ are function of the degree of melting. After, a plot of $T_{\text {extr }}\left(x_{\mathrm{m}}\right)$ versus $x_{\mathrm{m}}$ is built, as

Table 3 Solubility and melting parameters for PLA and plasticizer

\begin{tabular}{|c|c|c|c|c|c|c|c|c|c|}
\hline & \multicolumn{4}{|c|}{ Molar properties of polymer and plasticizers } & \multicolumn{5}{|c|}{ Properties of the blend } \\
\hline & $\begin{array}{l}\text { Molar volume/ } \\
\mathrm{cm}^{3} \text { mole }^{-1}\end{array}$ & $\begin{array}{l}\text { Molar } \\
\text { weight/g mole }{ }^{-1}\end{array}$ & Density $/ \mathrm{g} \mathrm{cm}^{-3}$ & $\delta / \mathrm{J}^{1 / 2} \mathrm{~cm}^{-3 / 2}$ & $\chi$ & $w_{\text {PLA }}$ & $\phi_{\mathrm{PLA}}$ & $\begin{array}{l}\left.T_{\mathrm{n}}^{0}\right|^{\circ} \mathrm{C} \\
\text { Flory-Huggins }\end{array}$ & $\begin{array}{l}T_{\mathrm{n}}^{0}{ }^{\circ} \mathrm{C} \\
\text { Hoffmann-Weeks }\end{array}$ \\
\hline PLA & 55 & 72 & 1.3 & 21.7 & & & & & $178 \pm 1{ }^{\circ} \mathrm{C}$ \\
\hline PEG & 357.3 & 414 & 1.16 & 22 & 0.35 & 0.8 & 0.78 & 170.5 & $170 \pm 1{ }^{\circ} \mathrm{C}$ \\
\hline CARD & 332 & 316 & 0.95 & 19.2 & 1.21 & 0.8 & 0.75 & 171 & $171 \pm 2{ }^{\circ} \mathrm{C}$ \\
\hline ECA & 364 & 374 & 1.03 & 18.1 & 2.33 & 0.8 & 0.77 & 174 & $173 \pm 3{ }^{\circ} \mathrm{C}$ \\
\hline
\end{tabular}




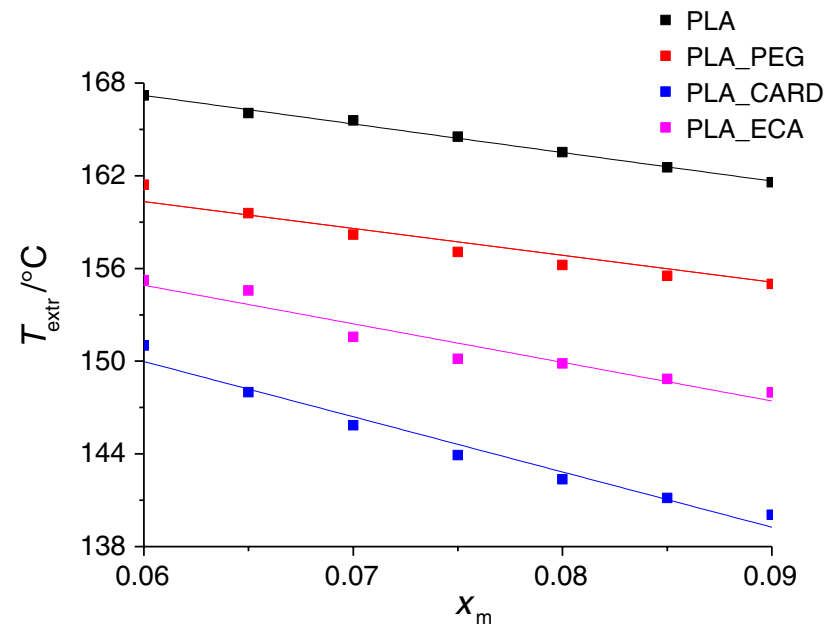

Fig. 6 Extrapolation at $x_{\mathrm{m}}=0$ for calculation of the true equilibrium temperature

reported in Fig. 6. As it can be observed, the plot was built at relatively low values of $x_{\mathrm{m}}$. In fact, keeping in mind that Eq. (3) holds for the crystals originally formed at $T_{\mathrm{c}}$, the error associated with the lamellar thickening/recrystallization increases with increasing $x_{\mathrm{m}}$. Finally, the true value of $T_{\mathrm{m}}^{0}$ is obtained by extrapolating the value of $T_{\text {extr }}\left(x_{\mathrm{m}}\right)$ at $x_{\mathrm{m}}=0$, which was done by linear fitting, also in view of the linear behavior observed in Fig. 6. The value obtained for neat PLA and plasticized PLA is reported in Table 3, showing that for PEG and CARD, a reduction of about $7-8{ }^{\circ} \mathrm{C}$ is found compared to neat polymer. For ECA, the reduction of $T_{\mathrm{m}}^{0}$ was found to be of about $5{ }^{\circ} \mathrm{C}$. The value reported for $T_{\mathrm{m}}^{0}$ of neat PLA was used in Eq. (1) in order to estimate the $T_{\mathrm{m}}^{0}$ of plasticized PLA; in all cases, a very good agreement is found between the values estimated by the Flory-Huggins equation and those experimentally determined by using the Hoffmann-Weeks plots. In particular, for PLA_PEG and PLA_CARD the lower values of $T_{\mathrm{m}}^{0}$ were found; the very small differences observed between the two samples is less than $1{ }^{\circ} \mathrm{C}$ and can be attributed to experimental, fitting and extrapolation procedure errors. For PLA_ECA, a higher value of $T_{\mathrm{m}}^{0}$ is found; according to the Flory-Huggins approach, this results from the higher $\chi$ value, which in turn results from a higher difference in the solubility parameters between ECA and PLA.

\section{Crystallization of plasticized PLA}

A typical DSC cooling scan for PLA plasticized by PEG and the two cardanol-derived plasticizers is reported in Fig. 7 at a cooling rate of $1.5^{\circ} \mathrm{C} \mathrm{min}^{-1}$. Under the same cooling conditions, no crystallization peak could be observed for neat PLA. Addition of PEG involves the presence of a sharp crystallization peak centered at about $71^{\circ} \mathrm{C}$, which indicates the

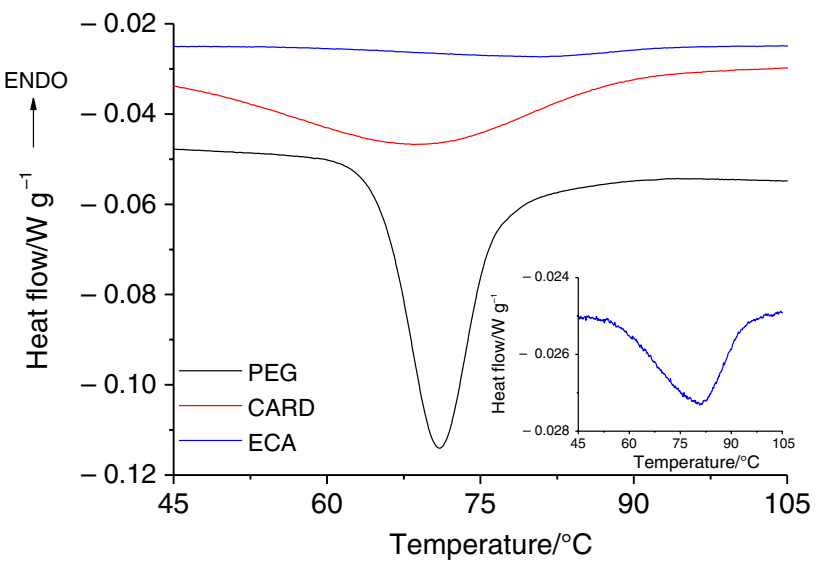

Fig. 7 Cooling curves of plasticized PLA at $1.5^{\circ} \mathrm{C} \mathrm{min}^{-1}$

enhanced rate of crystallization brought by the addition of PEG. On the other hand, cardanol also involves an enhanced crystallization compared to neat PLA; however, compared to PLA_PEG, the rate of crystallization is much lower, as well as the final degree of crystallinity attained at the end of the scan. Finally, PLA plasticized by ECA shows a very weak crystallization peak, better highlighted in the inset of Fig. 7, indicating a further reduction of the rate of crystallization compared to PLA_PEG and PLA_CARD.

Cooling tests were performed at different cooling rates. Initially, the enthalpy of crystallization was measured for each test as the integral of the curves reported in Fig. 7. After, the degree of crystallinity $x_{\mathrm{c}}$ at each temperature and different cooling rates were obtained by dividing the enthalpy of crystallization by the theoretical enthalpy of melting of $100 \%$ crystalline PLA, which is $93 \mathrm{~J} \mathrm{~g}^{-1}$ [35], corrected by the amount of PLA in the mixtures. The crystallization process was studied by means of the Ozawa equation; in our approach, this equation was modified in order to make the dimensions of the cooling function $\alpha(T)$ independent on the value of the Avrami exponent, $m$ [38]:

$\ln \left[-\ln \left(\frac{x_{\mathrm{c}, \text { limit }}-x_{\mathrm{c}}}{x_{\mathrm{c}, \text { limit }}}\right)\right]=m \ln (\alpha(T))-m \ln \beta$

where $\beta$ is the cooling rate and $m$ is the Ozawa exponent. In Eq. (6), a further modification was introduced. In fact, during the DSC scans, and also during the production of PLA samples for XRD and mechanical characterization, the maximum degree of crystallinity attained for the plasticized PLA was about 0.3, independently from the type of plasticizer used. Also in view of the uncertainties existing in the theoretical enthalpy of melting of PLA, related to different grades and crystalline forms [39], the degree of crystallinity has been divided by the limit value of $x_{\text {c,limit }}=0.3$. 
Initially, a plot of $\ln \left[-\ln \left(\frac{x_{\mathrm{c}, \text { limit }}-x_{\mathrm{c}}}{x_{\mathrm{c}, \text { limit }}}\right)\right]$ versus the cooling rate $\beta$ at each temperature allows to calculate the value of the $\mathrm{m}$ as the slope of the curve and the value of $\alpha(T)$. After, a plot of $\alpha(T)$ versus temperature, as reported in Fig. 8, shows for all the tested plasticizers a characteristic sigmoidal shape and was therefore fitted by a sigmoidal equation known as S-Richards function $[40,41]$ :

$\alpha(T)=a-a\left(1+\left(d_{\mathrm{m}}-1\right) \exp \left(-k_{\mathrm{m}}\left(T-T_{\mathrm{p}}\right)\right)\right)^{\frac{1}{1-\mathrm{d}_{\mathrm{m}}}}$

where $a$ is the value of $\alpha(T)$ measured at low temperatures, and $d_{\mathrm{m}}, k_{\mathrm{m}}$ and $T_{\mathrm{p}}$ are fitting parameters influencing the shape and the position on the temperature axis of the curve [41]. The fitting parameters obtained for the three samples are reported in Table 4.

The limiting value $\alpha(T)=a$ provides the maximum value of the degree of crystallinity which can be attained at each cooling rate:

$x_{\mathrm{c}, \max }=x_{\mathrm{c}, \text { limit }}\left(1-\exp \left[-\left(\frac{a}{\beta}\right)^{\mathrm{m}}\right]\right)$

The values obtained by Eq. (8), using the fitting parameters of Table 4, are reported in Fig. 9 together with the experimental data, showing a very good agreement, and therefore the suitableness of the developed approach. In particular, neglecting the $x_{\text {climit }}$ term, which is equivalent to set $x_{\mathrm{c}, \text { limit }}=1$, would yield in Fig. 9 that as $\beta$ approaches

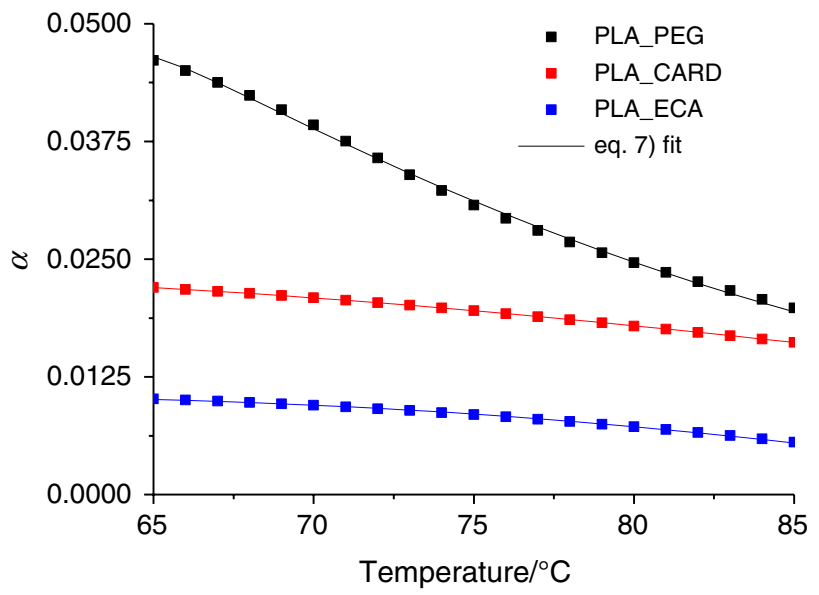

Fig. 8 Temperature evolution for the cooling function of plasticized PLA and model prediction according to Eq. (7)

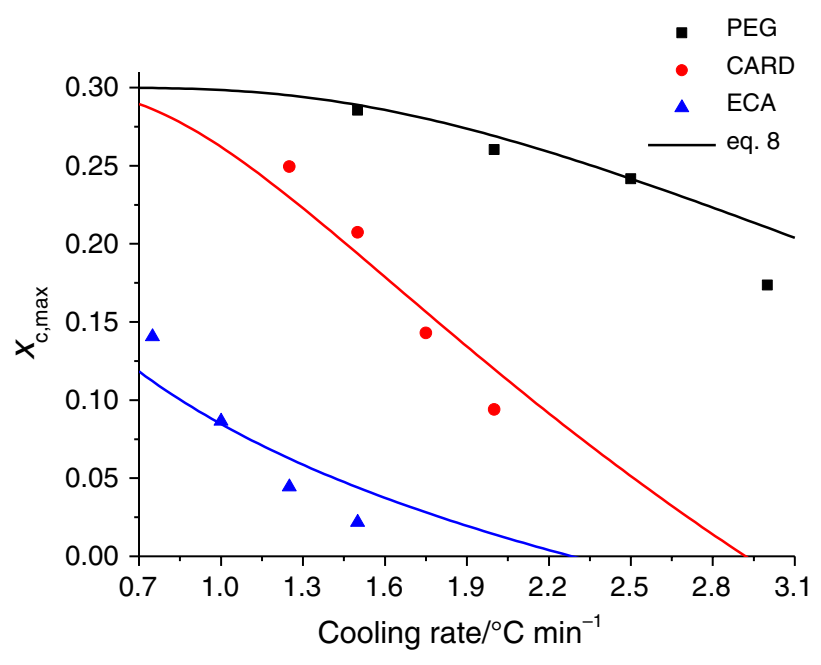

Fig. 9 Maximum degree of crystallinity as a function of cooling rate

$0, x_{\mathrm{c}, \max }$ approaches 1 , which is not the case of any of the plasticized PLA.

On the other hand, combination of Eqs. (6) and (7) allows to build the continuous cooling transformation (CCT) curves for each of the materials [38], reported in Fig. 10a-c for PLA_ PEG, PLA_CARD and PLA_ECA, respectively.

The CCT curves confirm the much faster crystallization kinetics of PLA_PEG compared to the PLA plasticized by the two cardanol derivatives. On the other hand, a comparison between CARD and ECA shows that the latter involves a slower crystallization compared to the former. In addition, the critical quenching rate, representing the cooling rate which determines the formation of an almost completely amorphous structure, was determined by Error! Reference source not found., by setting a maximum degree of crystallinity equal to 0.01:

$\ln \beta_{\text {quench }}=\ln a-\frac{1}{m} \ln (-\ln (0.967))$

The critical quenching curve obtained according to Eq. (9) is also reported in Table 4 and Fig. 10.

\section{Mechanical properties of PLA at different degrees of crystallinity}

Plasticized PLA samples produced by extrusion and film calendaring were shown to be completely amorphous, as
Table 4 Parameters for fitting of crystallization curves

\begin{tabular}{lllllll}
\hline & $m$ & $\mathrm{a} / \mathrm{K} \mathrm{s}^{-1}$ & $d$ & $\mathrm{~K} / \mathrm{K}^{-1}$ & $T_{\mathrm{P}} /{ }^{\circ} \mathrm{C}$ & $\beta_{\text {quench }} /{ }^{\circ} \mathrm{C} \mathrm{min}$ \\
\hline PEG & 1.90 & 0.0628 & 1.85 & 0.123 & 73.0 & 22 \\
CARD & 2.65 & 0.0132 & 1.25 & 0.147 & 70.0 & 2.8 \\
ECA & 2.87 & 0.0111 & 2.69 & 0.162 & 76.5 & 2.1 \\
\hline
\end{tabular}



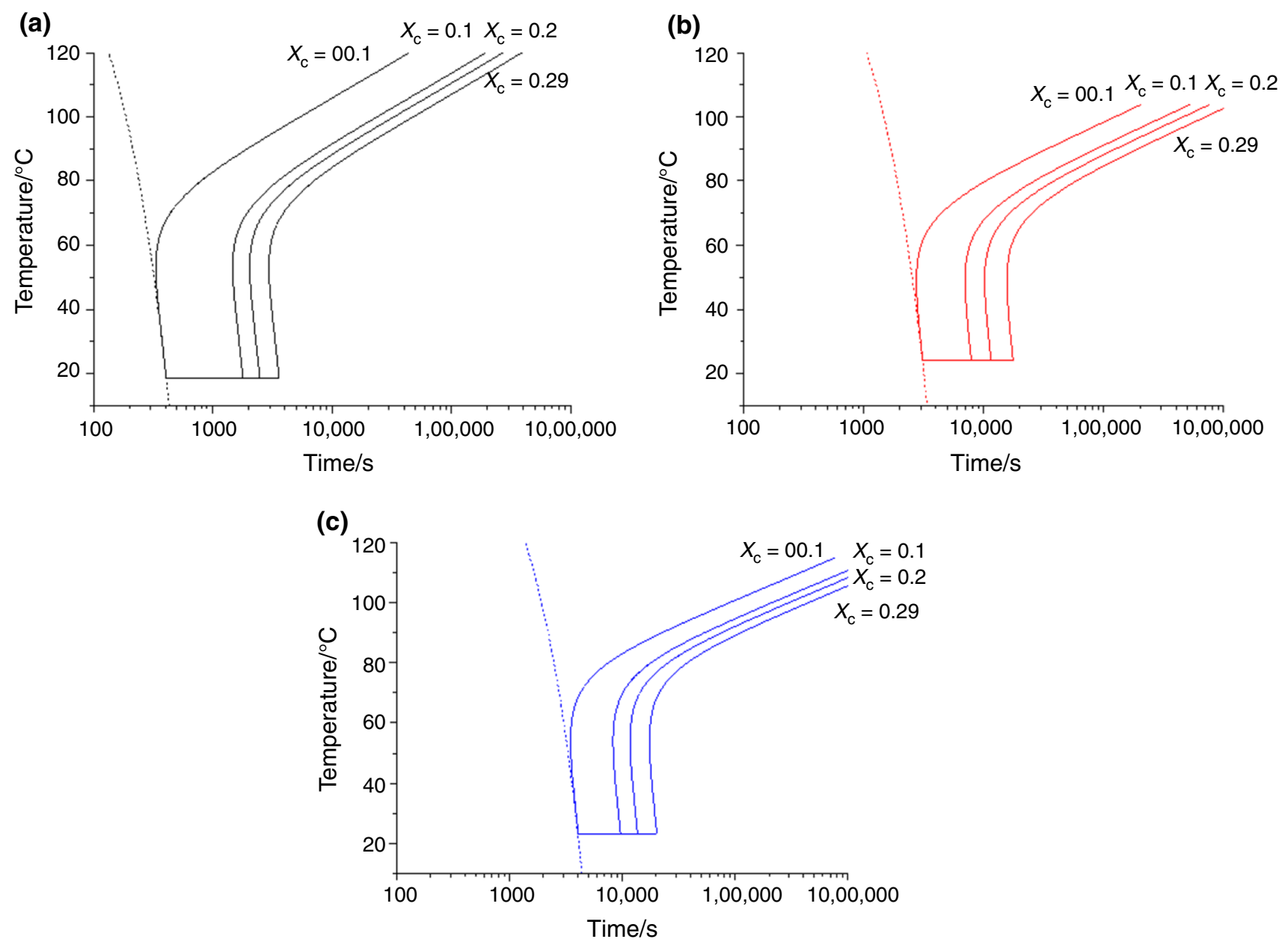

Fig. 10 CCT curve for a PLA_PEG; $\mathbf{b}$ PLA_CARD and $\mathbf{c}$ PLA_ECA

confirmed by XRD diffraction patterns of Fig. 11a. On the other hand, annealing process at $90{ }^{\circ} \mathrm{C}$ for $1 \mathrm{~h}$ allows to significantly increase the degree of crystallinity of plasticized PLA, as reported in Fig. 11b. However, the existence of a wide halo band in the plots of Fig. 11b indicates that it was not possible to obtain a completely crystalline sample; the degree of crystallinity for the three different samples, as estimated by the ratio between the area of the crystalline peak and the total are of XRD patterns, is about $0.31 \pm 0.02$, independently on the type of plasticizer.

Tensile properties for calendered and annealed samples are reported in Table 5. Calendered samples, being
Fig. 11 XRD patterns of a calendered samples and $\mathbf{b}$ annealed samples
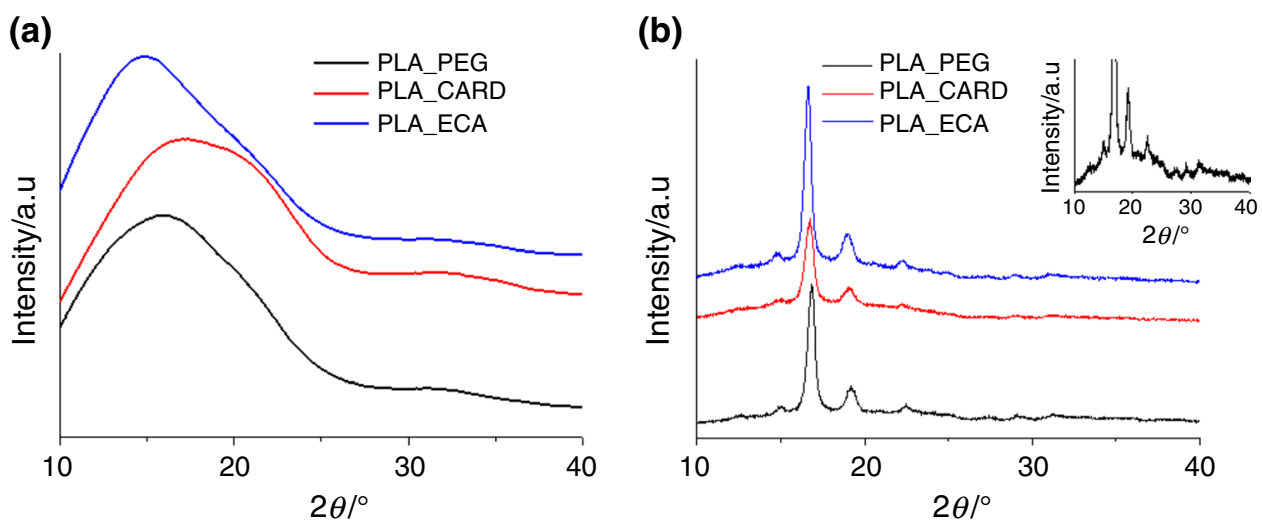
Table 5 Results of tensile tests

\begin{tabular}{lllr}
\hline & \multicolumn{1}{l}{$\sigma / \mathrm{MPa}$} & $\varepsilon / \%$ & \multicolumn{1}{c}{ E/MPa } \\
\hline Calendered samples & & & \\
PLA_PEG & $20.0 \pm 3.2$ & $215 \pm 41$ & $581 \pm 271$ \\
PLA_CARD & $20.5 \pm 5.8$ & $178 \pm 86$ & $691 \pm 321$ \\
PLA_ECA & $18.9 \pm 4.0$ & $281 \pm 64$ & $353 \pm 161$ \\
Annealed samples & & & \\
PLA_PEG & $18.9 \pm 3.6$ & $2.9 \pm 0.1$ & $962 \pm 270$ \\
PLA_CARD & $18.7 \pm 2.7$ & $2.0 \pm 0.2$ & $1156 \pm 462$ \\
PLA_ECA & $19.9 \pm 3.1$ & $2.5 \pm 0.2$ & $961 \pm 223$ \\
\hline
\end{tabular}

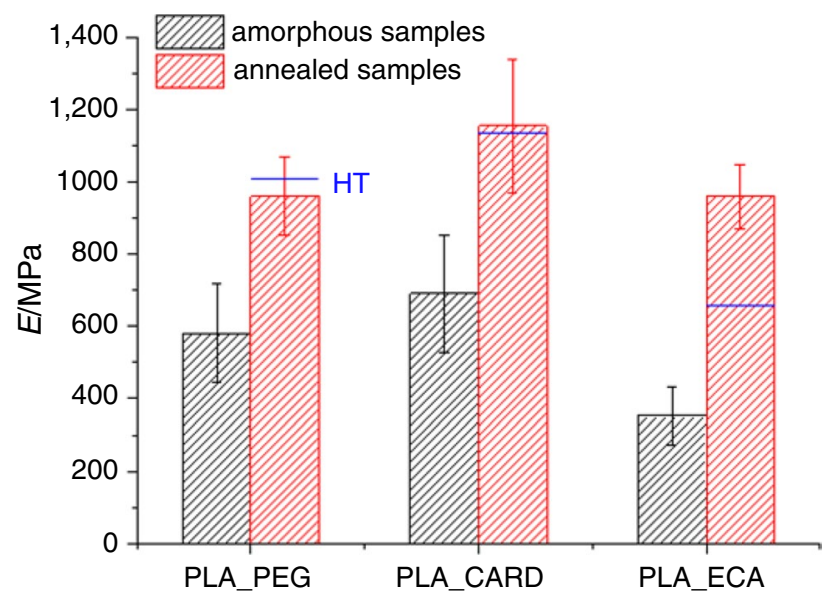

Fig. 12 Comparison of elastic modulus of calendered and annealed samples

completely amorphous, are characterized by very similar values of the tensile strength. Also, in view of the fact that the standard deviation is in the same range of the absolute differences between the average values, it is not possible to establish a correlation between the type of plasticizer and tensile strength. On the other hand, the strain at break increases going from PLA_CARD to PLA_PEG and PLA_ ECA. For all the tested samples, annealing involves a significant embrittlement, as highlighted by the dramatic reduction of the strain at break.

The effect of both plasticization and degree of crystallinity on the tensile modulus of PLA is shown in Fig. 12, where a comparison between the elastic moduli of fully amorphous plasticized PLA, obtained by calendaring, and $30 \%$ crystalline plasticized PLA, obtained after annealing, is reported. Under the same processing conditions, unplasticized PLA was found to be completely amorphous, with a tensile modulus of $1740 \mathrm{MPa}$. PLA plasticized by PEG shows a modulus of $580 \mathrm{MPa}$, which is lower than that of PLA plasticized by CARD, which is about $690 \mathrm{MPa}$. However, PLA plasticized by ECA shows the lowest value of the modulus, about $350 \mathrm{MPa}$, despite the higher value found for the glass transition. On the other hand, for all the tested samples, crystallization involves a significant increase in the tensile modulus. However, such increase is more significant for PLA_ECA. The modulus of the semicrystalline samples, $E_{\mathrm{SC}}$, can be obtained by the well-known Halpin-Tsai equation:

$\frac{E_{\mathrm{SC}}}{E_{\mathrm{am}}}=\frac{\frac{E_{\mathrm{C}}}{E_{\mathrm{am}}}\left(1+k_{\mathrm{HT}} \phi_{\mathrm{C}}\right)+k_{\mathrm{HT}}\left(1-\phi_{\mathrm{C}}\right)}{\frac{E_{\mathrm{C}}}{E_{\mathrm{am}}}\left(1-\phi_{\mathrm{C}}\right)+\phi_{\mathrm{C}}+k_{\mathrm{HT}}}$

where $E_{\mathrm{am}}$ and $E_{\mathrm{C}}$ are the moduli of fully amorphous and fully crystalline plasticized PLA, respectively, $\phi_{\mathrm{C}}$ is the volume fraction of the crystalline phase, and $k_{\mathrm{HT}}$ is the fitting constant which is usually assumed to be equal to 2 . In Eq. (10), it is implicitly assumed that the aspect ratio of the reinforcing crystalline phase is 1. For PLA_PEG and PLA_CARD, assuming a modulus of the crystalline phase $E_{\mathrm{C}}=3500 \mathrm{MPa}$ [42] yields $E_{\mathrm{SC}}=1010 \mathrm{MPa}$ and $E_{\mathrm{SC}}=1140 \mathrm{MPa}$, which are values very close to the experimental values. Instead, for PLA_ECA, the modulus estimated by the HT is much lower than the experimental value, indicating a higher modulus of the crystalline phase.

On the other hand, the line broadening at half the maximum intensity (FWHM) of the XRD patterns of Fig. 11 was estimated to be $0.54,0.55$ and 0.48 for PLA_PEG, PLA_ CARD and PLA_ECA, respectively. According to the Scherrer equation, a lower FWHM corresponds to thicker crystals. This is in agreement with the higher melting temperature found for PLA_ECA in Fig. 4, which also confirms the formation of thicker crystals. Accordingly, the higher modulus of the crystalline phase for PLA_ECA can be attributed to the formation of thicker crystals.

\section{Conclusions}

This work was focused on the study of the effect of different plasticizers on the thermal properties of PLA, and the influence on the mechanical properties. Glass transition behavior was studied by DSC analysis, showing comparable plasticizing effectiveness of all the plasticizers. The following estimation of $T_{\mathrm{g}}$ by the group contribution method showed an excellent agreement between experimental and predicted data, with the exception of PLA plasticized by PEG, showing a glass transition which is higher than the predicted value, which is indicative of partial miscibility between PLA and PEG at the studied concentrations. Furthermore, the study of the structural relaxation below $\mathrm{Tg}$ revealed a lower chain mobility for PLA_PEG compared to PLA_CARD and PLA_ECA samples.

The analysis of the melting peak revealed that the addition of plasticizers involved, in any case, a significant 
decrease in the equilibrium melting temperature of PLA. The influence of the plasticizer on the crystallization kinetic was also analyzed by DSC. Under the same cooling condition, the highest degree of crystallinity was attained with the addition of PEG, followed by CARD and ECA. Crystallization kinetics allowed to build CCT curves; in this case, the faster crystallization kinetics of PLA plasticized by PEG is highlighted by the fact that CCT curves are shifted at very low times. This involves very high critical quenching rate for PLA plasticized by PEG, which highlights potential difficulties in obtaining completely amorphous samples during processing. In contrast, for PLA plasticized by ECA the very low critical quenching rate indicates the possibility of obtaining completely amorphous samples even in processes characterized by low cooling rates.

Finally, tensile tests showed the effect of both plasticization and crystallinity on the modulus of PLA, showing the lowest value for amorphous PLA_ECA samples; PLA plasticized by CARD and PEG show substantially equivalent stiffness. Semicrystalline samples showed in any case a significant increase compared to amorphous samples. However, for PLA plasticized by PEG and CARD the modulus increase can be accurately predicted by micromechanics approach, namely Halpin-Tsai model, in the assumption that the semicrystalline samples behave like a particle reinforced composite, in which the amorphous phase corresponds to the matrix and the crystalline phase corresponds to the reinforcement. For PLA plasticized by ECA, the modulus increase due to the presence of a crystalline phase is much more relevant. This was, however, explained by considering that ECA plasticizer involved the formation of thicker crystals.

Funding Open access funding provided by Università del Salento within the CRUI-CARE Agreement.

Open Access This article is licensed under a Creative Commons Attribution 4.0 International License, which permits use, sharing, adaptation, distribution and reproduction in any medium or format, as long as you give appropriate credit to the original author(s) and the source, provide a link to the Creative Commons licence, and indicate if changes were made. The images or other third party material in this article are included in the article's Creative Commons licence, unless indicated otherwise in a credit line to the material. If material is not included in the article's Creative Commons licence and your intended use is not permitted by statutory regulation or exceeds the permitted use, you will need to obtain permission directly from the copyright holder. To view a copy of this licence, visit http://creativecommons.org/licenses/by/4.0/.

\section{References}

1. Heinrich LA. Future opportunities for bio-based adhesivesadvantages beyond renewability. Green Chem. 1866;2019:21.
2. Siracusa V, Blanco I. Bio-polyethylene (bio-pe), bio-polypropylene (bio-pp) and bio-poly(ethylene terephthalate) (bio-pet): recent developments in bio-based polymers analogous to petroleum-derived ones for packaging and engineering applications. Polymers. 2020;12:1641.

3. Pantani R, De Santis F, Sorrentino A, De Maio F, Titomanlio G. Crystallization kinetics of virgin and processed poly(lactic acid). Polym Degrad Stab. 2010;95(7):1148-59.

4. Greco A, Gennaro R, Timo A, Bonfantini F, Maffezzoli A. A comparative study between bio-composites obtained with opuntia ficus indica cladodes and flax fibers. J Polym Environ. 2013;21(4):910-6.

5. Lim LT, Auras R, Rubino M. Processing technologies for poly(lactic acid). Prog Polym Sci. 2008;33:820-52.

6. Jamshidian M, Tehrany EA, Imran M, Jacquot M, Desobry S. Poly-lactic acid: production, applications, nanocomposites, and release studies. Comp Rev Food Sci F. 2010;9(5):552-71.

7. Ge H, Yang F, Hao Y, Wu G, Zhang H, Dong L. Thermal, mechanical and rheological properties of plasticized poly (L-lactic acid). J Appl Polym Sci. 2013;127(4):2832-9.

8. Yu R, Zhang L, Feng Y, et al. Improvement in toughness of polylactide by melt blending with bio-based poly(ester)urethane. Chin J Polym Sci. 2014;32:1099-110.

9. Wypych G. Handbook of plasticizers. Toronto: ChemTec Publishing; 2004.

10. Rasal RM, Janorkarc AV, Hirt DE. Poly(lactic acid) modifications. Prog Polym Sci. 2010;35:338-56.

11. Vieira MG, Altenhofen da Silva M, dos Oliveira SL, Masumi B. Natural-based plasticizers and biopolymer films: a review. Eur Polym J. 2011;47:254-63.

12. Martin O, Averous L. Poly(lactic acid): plasticization and properties of biodegradable multiphase systems. Polymer. 2001;42:6209-19.

13. Ionescu M, Wan X, Bilic N, Petrovic ZS. Polyols and rigid polyurethane foams from cashew nut shell liquid. J Polym Environ. 2012;20:647.

14. Sakulsaknimitr W, Wirasate S, Pipatpanyanugoon K, Atorngitjawat P. Structure and thermal properties of polyurethanes synthesized from cardanol diol. J Polym Environ. 2015;23:216.

15. Besteti MD, Souza FG Jr, Freire DMG, Pinto JC. Production of core-shell polymer particles-containing cardanol by semibatch combined suspension/emulsion polymerization. Polym Eng Sci. 2014;54(5):1222.

16. Greco A, Ferrari F, Maffezzoli A, Del Sole R. Use of cardanol derivatives as plasticizers for PVC. J Vinyl Add Technol. 2018:24:E62-70.

17. Greco A, Ferrari F, Maffezzoli A. UV and thermal stability of soft PVC plasticized with cardanol derivatives. J Clean Prod. 2017;164:757-64.

18. Greco A, Ferrari F, Maffezzoli A. Thermal analysis of poly(lactic acid) plasticized by cardanol derivatives. J Therm Anal Calorim. 2018;134:559-65.

19. Ljungberg N, Wesslén B. Preparation and properties of plasticized poly(lactic acid) films. Biomacromolecules. 2005;6:1789-96.

20. Cangialosi D. Physical aging of polymers. In: Encyclopedia of polymer science and technology. 2018.

21. Miyata T, Masuko T. Crystallization behavior of poly(L-lactide). Polymer. 1998;39:5515.

22. Perego G, Cella CD, Bastioli C. Effect of molecular weight and crystallinity on poly(lactic acid) mechanical properties. J Appl Polym Sci. 1996;59:37.

23. Greco A, Ferrari F, Velardi R, Frigione M, Maffezzoli A. Solubility and durability of cardanol derived plasticizers for soft PVC. Int Polym Proc. 2016;31(5):577-86.

24. Porter D. Group interaction modelling of polymer properties. New York: Marcel Dekker; 1995. 
25. Van Krevelen DW. Properties of polymers. New York: Elsevier; 1990.

26. Camacho-Zuniga C, Ruiz-Trevino FA. A new group contribution scheme to estimate the glass transition temperature for polymers and diluents. Ind Eng Chem Res. 2003;42:1530-4.

27. Lu X, Weiss RA. Relationship between the glass transition temperature and the interaction parameter of miscible binary polymer blends. Macromolecules. 1992;25:3242-6.

28. Blanco I, Siracusa V. Kinetic study of the thermal and thermooxidative degradations of polylactide-modified films for food packaging. J Therm Anal Calorim. 2012;112:1-7.

29. Greco A, Gennaro R, Rizzo M. Glass transition and cooperative rearranging regions in amorphous thermoplastic nanocomposites. Polym Int. 2012;61:1326-33.

30. Greco A, Rizzo M, Maffezzoli A. Effect of the addition of organically modified nanofiller on the relaxation behavior of a thermoplastic amorphous matrix. Thermochim Acta. 2012;543:226-31.

31. Tábi T, Sajó I, Szabo F, Luyt A, Kovacs J. Crystalline structure of annealed polylactic acid and its relation to processing. Express Polym Lett. 2010;4:659-68.

32. Greco A, Ferrari F, Maffezzoli A. Thermal analysis of poly(lactic acid) plasticized by cardanol derivatives. J Therm Anal Calorim. 2018;134(1):559-65.

33. Muthukumar M. Nucleation in polymer crystallization. In: Rice SA, editors. Advances in chemical physics. 2004. https://doi. org/10.1002/0471484237.ch1.

34. Guo W, Shao J, Ye X, Sun P, Meng C, Li Z, Zhengcand Z, Yan C. The difference of equilibrium melting point between poly(L-lactic acid) and poly(L-lactic acid)/poly(D-lactic acid) blends: cases with three molecular weights. Polym Int. 2019;68:271-6.
35. Battegazzore D, Bocchini S, Frache A. Crystallization kinetics of poly(lactic acid)-talc composites. Express Polym Lett. 2011;5(10):849-58.

36. Yamada K, Hikosaka M, Toda A, Yamazaki S, Tagashira K. Equilibrium melting temperature of isotactic polypropylene with high tacticity: 1. Determination by differential scanning calorimetry. Macromolecules. 2003;36:4790-801.

37. Juhász P, Varga J, Belina K, Marand H. Determination of the equilibrium melting point of the form of polypropylene. J Therm Anal Calorim. 2002;69:561-74.

38. Greco A, Maffezzoli A. Analysis of the suitability of polylactic acid in rotational molding. Adv Polym Technol. 2015;34(3):21505.

39. Righettia MC, Gazzano M Di, Lorenzo ML, Androsch R. Enthalpy of melting of $\alpha^{\prime}$ - and $\alpha$-crystals of poly(L-lactic acid). Eur Polym J. 2015;70:215-20.

40. Seber GAF, Wild CJ. Nonlinear regression. New York: Wiley; 1989. p. 332-7.

41. Greco A, Maffezzoli A. Statistical and kinetic approaches for linear low-density polyethylene melting modeling. J Appl Polym Sci. 2003;89:289-95.

42. Farah S, Anderson D, Langer G. Physical and mechanical properties of PLA, and their functions in widespread applications: a comprehensive review. Adv Drug Deliv Rev. 2016;107:367-92.

Publisher's Note Springer Nature remains neutral with regard to jurisdictional claims in published maps and institutional affiliations. 